\title{
Correcting the Errors in the Writing of University Students' in the Comfortable Atmosphere
}

\author{
Tuanhua Lu \\ English Department, XianYang Normal University, XianYang 712000, China \\ E-mail: thlu029@163.com
}

\begin{abstract}
This paper analyzed the common errors in university students' writing. At the same time,it showed some methods based on activities designed to give students practice in these problem areas. The activities are meant to be carried out in a comfortable, non-threatening atmosphere in which students can make positive steps toward reducing their errors and increasing their motivation to write in English.
\end{abstract}

Keywords: Common Errors, Error Analysis, Correction

\section{Introduction}

Teachers of composition or writing classes in Chinese universities are generally faced with students who have acquired a certain amount of English vocabulary and grammar, but have rarely put that knowledge to practical use (Wachs, 1993). In many cases, the major portion of these students' English education has been filled with translating words, phrases, and sentences from Chinese to English with often very strange results.

The challenge for the composition teacher is to use error analysis to find ways to activate in a meaningful way the passive knowledge the students possess, as well as to help the students become more proficient while working to eliminate some of their more common errors.

\section{Error and Error Analysis}

\subsection{What is "error"?}

The term "error" is used to refer to a form of structure that a native speaker deems unacceptable because of its inappropriate use (Klassen, 1991) or the use of a linguistic item in a way in which a fluent or native speaker of the language regards as showing faulty or incomplete learning (Richards, 1985).Different person has different ideals on it. Anyway, people's attitudes towards it have changed as time goes on.

\subsection{A Historical Perspective}

Over the past 40 years, there has been a shift in pedagogical focus from preventing errors to learning from errors. During the era of audiolingualism in the 1950s and 60s, language learners had to repeat pattern drills and grammatical structures in a mechanistic fashion. By memorizing the "correct model", it was hoped that error could be avoided because errors were considered signs of failure in the learning process.

In the late 1960s, however, language teaching became more humanistic when studies of cognitive psychology influenced the theory of language acquisition. Language learning was finally acknowledged to be based on active mental involvement and not mere habit formation. Students were then encouraged to learn by communicating in the target language and not by merely repeating grammatical items.

Subsequently, a more positive attitude towards errors has also emerged. Now, errors are viewed as a natural and important part of learning because they can yield information about a student's progress in learning a language. This positive attitude towards errors is especially important in the wake of the Communicative Approach to language learning and teaching in the 1990s.

Language teaching in China is currently focusing on the teaching and learning of the four language skills of listening, speaking, reading and writing. Since grammar is seen only as a means to an end, some learners tend to de-emphasize its importance and in the process, make many more errors. Thus, rekindling interest in the area of learner errors in the 1990 s can be considered a timely move. Teachers who can analyze and treat errors effectively are better equipped to help their students become more aware of their errors. Ultimately, the use of error analysis and appropriate corrective techniques can aid effective learning and teaching of the English Language.

\subsection{What is the "error analysis"?}

As is shown that teachers and linguists become more and more positive towards errors. So it is necessary to make an analysis of errors in order to correct them. 
Error analysis (henceforth, EA) is the identification, description and explanation of errors either in its spoken or written form. Five stages are involved in EA. First, one has to identify the errors. To do this, one has to differentiate lapses from genuine errors of competence. Second, an initial analysis and description of the errors is made based on a grammatical model. Third, the errors are classified according to categories or sub-categories like the following: Substance-errors, Text-level errors, Discourse level errors. Fourthly, an explanation may be provided as to why the errors have been made. Lastly, the errors are evaluated to determine how much they deviate from the target language norm, to what extent they affect communication and which method of correction can be most effectively meted out. With the treatment of errors in the written form, however, accuracy should be a strict criterion to adhere to due to the demands of written examinations.

\section{The Reasons of Errors.}

The sources of errors are too many, but I think the most important and obvious are the following:

Transfer of Native language. Native language transfer is an unavoidable factor in writing. There is overwhelming evidence that "language transfer" is indeed a real and central phenomenon that must be considered in any full account of the second language acquisition process"(Gass and Selinker,1992,7). When Chinese college students learn English, especially in their English writing, transfer is manifested at various levels, such as lexis, syntax, and discourse. Chinese students always use the rules, the thinking way of Chinese in their English writing. For example:

Pro-drop: Lagguage may differ as to whether or not they require an overt pronoun in certain environments. One of the most striking differences between English and Chinese is that English necessitates an overt subject in sentences except imperatives. By contrast, if the referent can be grammatically and pragmatically retrieved,Chinese allows omission of subject pronouns in a sentence(Xu,1992). This"pro-drop"phenomenon, common in written Chinese,differs from English which regards subject less clauses as ungrammatical .Therefore, pro-drop sentences in English writings by Chinese writers can be constructed as L1 transfer, and it can be extended to the subject in a sentence as well.

Example: If have no money, you can do nothing.

I tried hard to listen, but I just can not hear.

Overgeneralization. When students apply a grammatical rule across all members of a grammatical class (e.g. verbs) without making the appropriate exceptions. For example, goed (meaning went), a form they are unlikely to have heard, suggesting that they have intuited or deduced complex grammatical rules (here, how to conjugate regular verbs) and failed only to learn exceptions that cannot be predicted from a knowledge of the grammar alone. In their writing works, many of the errors are caused because of overgeneralization.

Fossilization. At a certain stage students cease to learn new aspects of the TL. Although perhaps capable to express themselves in a grammatically correct way, students here do not proceed to explore the great reservoir of language any further in order to express themselves in a more refined and sophisticated manner. It causes many unstandard way of expressing in their writing.

Simplification. Simplification is a result of an attempt to adjust the language behavior to the interests of communicative effectiveness.

In order to avoid redundancy, students always use simplification. For instance, they use comed, goed instead of came and went. So they often make errors.

\section{The Correction of Errors}

With the above reasons in mind, I think it is necessary to find stragies to correct errors according to their different types.

\subsection{The Already Existed Methods of Error Correction}

There is no single method of dealing with the errors made by students. Among some of the conventional practices of teachers are to mark every error, provide the correct answer for errors made, mark the first and only draft or work written by students, make general comments, make students re-write the corrected version several times over and view errors as signs of failure. In contrast, recent literature contains several suggestions for correcting written errors effectively in answer to the question of "to red-pen or not to red-pen" (Josephson, 1990). Some of the methods of EC advocated are the use of peer marking/editing, selective marking, code correction, correction based on the process approach to writing, effective and specific comments, a checklist of limited common errors, different colored inks, discussion of errors on tape and direct versus discovery-type of marking.

Underlining errors is a common way of handling errors. However, Lim (1991) proposes that students be allowed to work at these errors themselves with the help of their peers. Peer-marking/editing is especially useful in the 
first draft of the written work. Here, students are given the responsibility to edit each other's work individually or in a group before handing in the final draft to the teacher. Besides being fun for students to be allowed to correct and learn from errors other than their own, it also reduces the need for too many red markings from the teacher. Here, students must be briefed on how to edit the work of their peers. A mini lesson lasting only five minutes of class time may be presented at the beginning of the class on a regular basis. For example, the teacher could write several erroneous sentences on the board which is to be analyzed by the students themselves. This is a way of making more economical use of time where errors can form the basis for teaching.

Parents should not be too concerned or alarmed if every error in their children's written work is not corrected by the teacher. Teachers also should not mark every error just because it is expected of them or because they believe it is an indication of dedication (Singh, 1991). This is because over-correction can be a very tedious experience for the teacher (resulting in a demoralizing experience for the student.

Parents should not be too concerned or alarmed if every error in their children's written work is not corrected by the teacher. Teachers also should not mark every error just because it is expected of them or because they believe it is an indication of dedication (Singh, 1991). This is because over-correction can be a very tedious experience for the teacher.

\subsection{The use of the easy way to correct}

With the above problem areas in mind, I think activities that give the students practice in correct usage within a meaningful context should be used. Creating a comfortable classroom atmosphere is extremely important if the students are to gain anything from the selected activities and retain what they are learning. The importance of the social climate of the classroom and the teacher's role in fostering it has been well-documented.

In research conducted at UCLA the ESL (English as a Second Language) faculty chose social climate as the most important among 11 factors relating to language teaching (Bailey, 1976). Hunter (1974) has suggested that the teacher is the most important variable in the classroom. In reviewing literature on teacher effectiveness, Brophy and Good (1974) found that teacher warmth and enthusiasm consistently show a positive correlation with student achievement. Bailey and Celce-Murcia (1979: 316) maintain that "what the teacher says and does is so significant in establishing classroom atmosphere that it can outweigh the effects of materials, methods, and educational facilities."

What does creating an atmosphere where affective filters 3 are lowered and meaningful learning can take place have to do with setting up activities designed to help eliminate some of the problem areas listed previously? It means the teacher should use activities that include him in the community of the classroom, and that he should take an active role in the interaction of the community members. The activities should involve exchanges of information concerning the members' own lives, feelings, hopes, dreams, and opinions, as well as frequent usage of the patterns the students have problems with.

So here I will show some methods that I have been taught in my writing. I find they are very useful and extremely helpful.

\subsubsection{Substance-errors.}

These kinds of errors are mainly caused by students' incorrect memory. So the most important thing is to make students recite these correctly. I intend to group students into two teams. One is A and the other is B. Letting them exchange their writings and correct errors of opponents'. Students must find their opponents' errors as many as possible and give the right ones .If not, teacher will give some punishments to them. During this process, teacher should shoot students acts and let them watch .In this method, students may recognize their errors when they recall their stupid actions .Teachers may let students watch their own film in order to make them find out their errors. This method may let students have a deep memory of their errors.

\subsubsection{Text-level}

Error lists form the central component of the writing program. Their use is designed to facilitate students' grammar consciousness-raising by the use of extended descriptions.

The system for using the error lists is simple. Concentrating on the types of common errors outlined earlier, the teacher takes about 20 examples of these errors from the student papers, makes a list, and hands out copies of the list. In order to retain the anonymity of the writers and avoid singling anyone out, changes in verbs and nouns can easily be made. During the first half of the class the students work in small groups discussing and trying to correct the errors. During the second half of the class the teacher gives a lecture on the errors.

The lecture is intended to be filled with as much humor as possible. This humor is derived from what a native speaker's reactions might be to some of the error-ridden sentences on the list. Below are some typical errors 
taken from student papers and examples of how a teacher might present them.

1). "My family is four": The teacher demonstrates a native speaker's reaction: "That's interesting. What an unusual family you have. Let's see. Your father is four years old. Your mother is four years old. Your brother is four years old. Everyone is four years old! How did you get to be 18 years old?" The teacher then explains the error and writes the correct sentence on the board (e.g., "There are four people in my family.").

2). "Son is elementary school": The teacher draws a woman, two little girls, and a building on the board, then writes a name by each figure. He acts out a conversation with an imaginary stranger: "Hello, Mr. Smith. I'd like you to meet my family. This is my wife Sally (pointing to the woman figure). These are my two daughters Betty and Sue (pointing to the girl fugures). And this is my son John (pointing to the building figure). He is an elementary school!" The teacher then explains the error and writes the correct sentence on the board (e.g., "My son is an elementary school student.").

3). "He was died his wife": The teacher writes these sentences on the board: "He was killed by his wife." "His wife was killed by him." "He killed his wife." "His wife killed him." "He was dead, but now he is alive." "His wife was dead, but now she is alive." "He died." "His wife died." The teacher acts out an exchange between person A, who says, "He was died his wife" and person B, who goes through all the possible interpretations, becomes increasingly frustrated, and finally begins jumping up and down shouting, "Who died?" The teacher falls to the ground with a fake heart attack, gets up, smiles at the class, and says "His wife died."

There is a method to this madness. First of all, humor is often an underused and unexploited variable in creating a positive classroom atmosphere. Bailey and Celce-Murcia (1979: 318) encourage the use of humor:

Opportunities for humor should be exploited....If there is a cartoon, joke, or anecdote that pertains to the lesson, the teacher should share it with the group. In a study that compared outstanding teachers with beginning and "typical" teachers in inner-city schools, Moskowitz and Hayman (1974) found that the best teachers used humor in their initial contacts with students....In another study that compared outstanding and typical teachers, Moskowitz (1976) found that outstanding teachers smiled more than typical teachers, and there was more laughter in their classrooms.

Secondly, the type of humor used in the error correction lecture is designed to create strong, often exaggerated images that have the potential to touch the students on affective or emotional levels.

In giving the lecture, it is not necessary to inject humor into the correction of each error on the list. The important thing is to use humor as a teaching tool where applicable. Any teacher should be able to come up with a few humorous explanations within a single list of errors.

There is one point the teacher must always keep in mind. It is essential not to turn his interpretations into any kind of condescending or derogatory comment. Errors should always be seen as learning tools. If a positive atmosphere has been created and the teacher is seen as enjoying his experience with the students, it is unlikely any negative and unwanted impressions will be derived from the use of humor in correcting errors.

"Which Do You Prefer and Why?" (Ur, 1988: 72): Write on the board 10 sets of two or three words expressing concepts likely to arouse positive or negative reactions (e.g., snakes, spiders, crocodiles; mornings, afternoons, evenings; mud, sand, rocks; etc.). Ask the students to express and justify their preferences (e.g., "I prefer snakes to spiders because they are more colorful and graceful."). This activity can be done in the first person or in an interview format in which students write sentences reporting on their classmates' preferences. It is a good activity for practicing.

\subsubsection{Discourse level errors}

These kinds of errors are based on the whole text. So the first thing is to find ways from the angle of the whole text. I think the following examples are the good ways of correcting:

1). "Sweet Consequences" (Hadfield, 1990): Cut up about 40-50 strips of "reason" phrases and "consequence" phrases (e.g., "I brought my umbrella" and "it was raining"). Put the students into small groups and have them match the phrases in 20-25 "so" sentences and 20-25 "because" sentences (e.g., "It was raining so I brought my umbrella" or "I brought my umbrella because it was raining."). This activity is good for raising students' consciousness of the usage of subordinating conjunctions, as well as for helping reduce their tendency to start too many sentences with conjunctions.

2). "The Big If": Hand out copies of a picture that shows several accidents about to happen that could set off a chain of events (e.g., a girl about to step on a banana peel, a car coming around a corner where a pedestrian is crossing the street, a window cleaner about to knock over a bucket of water on some people below him, etc.). Put this pattern on the board: "If + subject (relative clause) + present tense, subject + modal of probability + 
dictionary form of verb." Have the students (in pairs or small groups) make sentences describing what might happen in the picture. The students must write at least three more possible consequences of the first "if" (e.g., "If the girl who is walking in the right side of the picture steps on the banana peel, she will fall down. If she falls down, she might break her arm. If she breaks her arm, she might go to a hospital, meet a handsome doctor, fall in love, and get married."). This activity provides practice of the first conditional, relative clauses, modals of probability, and subject-verb agreement.

3). "Before and After" (Ur, 1988: 198-201): Hand out a picture of a room that needs to be cleaned. Have the students in small groups make a list of all the things that should be done (e.g., "The TV should be turned off." "The bed needs to be made." etc.). Hand out a second picture showing the room after it has been cleaned. There should be at least two new items in the room. Have the groups make a second list of what has been done (e.g., "The TV has been turned off." "A picture has been hung on the wall."). This activity provides practice in modals of necessity, present perfect tense, passives, and definite and indefinite articles. It is especially useful for showing students that when new information is introduced, the indefinite article "a" is often used.

The main considerations for using such activities are that the activities should focus on common errors at the sentence level or discourse level encourage student creativity and input, and allow for student interaction and problem-solving. The teacher should walk around the classroom giving help, making suggestions, and joining in from time to time.

\section{Conclusion}

This paper has described some of the common errors that students in Chinese university writing classes make and some methods based on activities designed to give students practice in these problem areas. The activities are meant to be carried out in a comfortable, non-threatening atmosphere in which students can make positive steps toward reducing their errors and increasing their motivation to write in English. The focal points of the activities are the teacher's influence on classroom atmosphere, the use of humor and extended descriptions when explaining grammatical points and errors.

For teachers who don't feel uncomfortable in the role of occasional entertainer, have a commitment toward creating an atmosphere in which affective filters are lowered, and sincerely enjoy the time spent with students, the activities outlined in this paper can be effective in raising students' consciousness of errors, reducing the number of common errors they make, and improving their English writing ability.

\section{References}

Bailey, K. (1976). The Use of Two Observation Instruments in Supervised ESL Teaching. Unpublished MA thesis. University of California, Los Angeles.

Bailey, K. \& Celce-Murcia, M. (1979). Classroom skills for ESL teachers. In M. Celce-Murcia \& L. McIntosh (Eds.), Teaching English as a Second or Foreign Language (pp. 315-330). Rowley, Mass.: Newbury House.

Hadfield, J. (1990). Advanced Communication Games. Hong Kong: Thomas Nelson \& Sons.

Hunter, M. (1974). Piagetian Theory Applied to Assessment of the Teaching Process. Unpublished manuscript. University Elementary School, University of California, Los Angeles.

Klassen, J. (1991). “Using Student Errors for Teaching”, FORUM, Vol. XXIX, No. 1, Jan.

Michaelides, N. (1990). "Error Analysis: An Aid to Teaching”, English Teaching Forum, Vol. XXVIII, No.4, Oct.

Moskowitz, G. \& Hayman, J. (1974). Interaction patterns of first year, typical and "best"teachers in inner-city schools. Journal of Educational Research, 67: 5.

Moskowitz, G. (1976). The search for excellence. Paper presented at the tenth annual TESOL convention. New York

Singh. (1991). Sunday Star (Kuala Lumpur) 28 July 1991, p.25.

Teh, G.C. (1989). "An Analysis of Errors in Constructed Sentences of Malay Students at the International Islamic University”, M.Ed. TESL Dissertation, University of Malaya.

Ur, P. (1988). Grammar Practice Activities: A Practical Guide for Teachers. Cambridge: Cambridge University Press

Wachs, S. (1993). Breaking the writing barrier: Approaches to the composition class. In P. Wadden (Ed.), A Handbook for Teaching English at Japanese Colleges and Universities. Oxford: Oxford University Press. 